\title{
DA COMPLEXIDADE À SIMPLIFICAÇÃO NA IDENTIFICAÇÃO DA RATIO DECIDENDI: SERÁ MESMO QUE ESTAMOS A FALAR DE PRECEDENTES NO BRASIL?
}

\section{FROM COMPLEXITY TO OVERSIMPLIFICATION ON IDENTIFYING A DECISION'S RATIO DECIDENDI: ARE WE REALLY TALKING ABOUT PRECEDENTS IN BRAZIL?}

\section{LENIO LUIZ STRECK}

Professor Titular do Programa de Pós-Graduação em Direito da Unisinos, RS, e Unesa, RJ. Doutor e Pós-Doutor em Direito. Ex-Procurador de Justiça (MP/RS). Membro Catedrático da Academia Brasileira de Direito Constitucional - ABDCONST. Professor Emérito da EMERJ/RJ. Presidente de Honra do Instituto de Hermenêutica Jurídica (IHJ). Advogado. E-mail: lenios@globomail.com.

IGOR RAATZ

Pós-doutor, doutor e mestre em Direito pela Universidade do Vale do Rio dos Sinos UNISINOS. Especialista em processo civil pela Academia Brasileira de Direito Processual Civil - ABDPC. Membro do Dasein - Núcleo de Estudos Hermenêuticos. Subdiretor de eventos da ABDPro - Associação Brasileira de Direito Processual. Professor da Universidade Feevale - Novo Hamburgo, RS. Professor em cursos de pós-graduação direito processual civil. Advogado. E-mail: igor@raatzanchieta.com.br

GILBERTO MORBACH Mestrando em Direito Público, como bolsista CNPq, pela Universidade do Vale do Rio dos Sinos (Unisinos/RS). Bacharel em Direito pela Universidade Feevale (Feevale/RS). Membro do Dasein - 


\title{
RESUMO
}

O presente ensaio aborda a questão dos mecanismos vinculantes brasileiros presentes no Código de Processo Civil de 2015 — os quais, equivocadamente, vêm sendo comparados aos precedentes do common law - a partir de uma pesquisa histórica e explanatória acerca da identificação da ratio decidendi de uma decisão. Além disso, o artigo aborda as diferentes interpretações, comumente ignoradas no Brasil, acerca do precedente nos sistemas anglo-saxões. Em síntese, procuramos demonstrar as incompatibilidades dos (supostos) precedentes brasileiros em comparação com o instituto de origem: o stare decisis genuíno dos países do common law.

PALAVRAS-CHAVE: Precedentes; Ratio decidendi; Código de Processo Civil de 2015.

\begin{abstract}
This essay discusses the binding mechanisms in Brazilian law — present in the 2015 Brazilian Code of Civil Procedure - , which have been erroneously taken as commonlaw-like precedents, from a historical, explanatory research of the identification of a decision's ratio decidendi. Besides, the article discusses different interpretations regarding what it means for a common law precedent to be binding - interpretations that are more frequently than not ignored in Brazil. In short, we seek to demonstrate how incompatible the (so-called) Brazilian precedents are in comparison to the original common law stare decisis, the original institute.
\end{abstract}

KEYWORDS: Precedents; Ratio decidendi; Brazilian Code of Civil Procedure of 2015.

\section{INTRODUÇÃO}

O alvoroço doutrinário e legislativo em favor dos "precedentes vinculantes" [sic] é somente mais um sintoma do modo como, no Brasil, o Direito é encarado a 
partir de constantes simplificações. Enquanto na prática forense dos países do common law grande parte das discussões de advogados e juízes estão ao redor da rotulação de um argumento como ratio ou como dictum (LOPES FILHO, 2016, p. 166), no Brasil, o problema da identificação da ratio decidendi de uma decisão - e, portanto, do seu elemento de vinculação - costuma objeto de apropriação pelo próprio Tribunal que proferiu referida decisão. Não por acaso, precedentes tornaramse, no Brasil, teses construídas a partir de um caso como pretensão vinculante para o futuro, como se fossem produtos legislativos. $E$ isso não parece incomodar boa parte da doutrina, que, em vez de se rebelar diante de uma espécie de subversão judicial do princípio da separação de poderes, prefere chancelar tais práticas. Que não se diga que os receios quanto à possível subversão da trias politica são infundados: pesquisadores no âmbito próprio do common law e do civil law relacionam, expressa e diretamente, a "rejeição do precedente como fonte [direta] de Direito", típica dos países de tradição romano-germânica, com a "separação estrita de poderes de Montesquieu na França pós-Revolução" (BANKOWSKI et. al., 2016, pp. 482-483).

No presente ensaio, assim, pretendemos revelar como a questão da identificação da ratio decidendi constitui um problema extremamente complexo para o common law e, ao mesmo tempo, alvo de infindáveis simplificações no Brasil. Não que muitos dos doutrinadores brasileiros, defensores de um sistema de precedentes, desconheçam o debate existente no common law acerca do tema; seria leviano acusar de ingênuos os precedentalistas brasileiros. Há, porém, um abismo entre as considerações teóricas a respeito do tema e sua incorporação na prática judicial brasileira - crítica que também pode ser endereçada ao Código de Processo Civil brasileiro, o qual, com seu art. 927, pretendeu criar um rol de mecanismos vinculantes, ou de falsos precedentes, que já nasceriam como o rótulo da vinculatoriedade antes mesmos dos casos em que seu elemento vinculante seria identificável. Por isso, embora o tema já não seja mais novidade, a necessidade de realizar uma crítica a seu respeito permanece incontestável. ${ }^{1}$

\footnotetext{
${ }^{1}$ Para um aprofundamento acerca do tema, ver STRECK, 2018.
} 


\section{A RATIO DECIDENDI DA DECISÃO: "PRECEDENTE” BRASILEIRO E STARE DECISIS ANGLO-SAXÃO}

O precedente, sabemos, envolve uma decisão passada que é seguida em um caso posterior, em razão de ambos os casos serem similares. $O$ instituto deve sua origem aos sistemas jurídicos típicos do common law, já que esses ordenamentos são desenvolvidos por juízes, Cortes e Tribunais (CAENEGEM, 2010, passim). Evidentemente, isso levanta uma série de perguntas: quando dois casos são "similares", nos termos exigidos para que se configure um precedente? Por que uma decisão no caso pretérito deve afetar a do caso subsequente? Quais são os elementos vinculantes que dão caráter de precedente a uma decisão? A decisão precedente tem sempre, e sempre terá, força vinculante? Em que medida?

O precedente - isto é, uma decisão a ser considerada no julgamento de casos futuros semelhantes - , seja no common law, seja em sua (tentativa de) apropriação brasileira, bem como as possíveis respostas a todas essas questões suscitadas, envolve os conceitos de obiter dicta e ratio decidendi (COLLIER, 1988; DUXBURY, 2008, p. 67). Em linhas gerais, obiter dicta são aqueles argumentos utilizados pelos juízes, ou mesmo comentários en passant, que são "prescindível[eis] para o deslinde da controvérsia". Não há muitos problemas até aí. A ratio decidendi, por sua vez, é o que "constitui a essência da tese jurídica suficiente para decidir o caso concreto" (CRUZ E TUCCI, 2004, pp. 175, 177; DUXBURY, 2008, p. 67). Evidentemente, a ratio decidendi inaugura um problema complexo; tanto é que a questão da identificação da ratio decidendi é algo que a doutrina do common law já debateu muito (e ainda debate).

No Brasil, por outro lado, a questão parece ser simplificada. Em artigo publicado por Luís Roberto Barroso e Patrícia Mello (2016), referidos autores consideram a ratio decidendi como "uma descrição do entendimento jurídico que serviu de base à decisão". Em linha muito similar, Daniel Mitidiero (2016) dispõe que "a ratio decidendi de uma questão constitui o resultado de uma generalização das razões invocadas pela corte que julgou o caso devidamente apreendido pelo juiz ou pela corte que deve julgar o novo caso". Disso se segue que, para os precedentalistas, "[...] da solução de um caso concreto (particular) extrai-se uma regra 
de direito que pode ser generalizada" (DIDIER JÚNIOR, 2013). É o que Marinoni, Mitidiero e Arenhart $(2015$, pp. 605, 611) chegam a chamar de "mandamentos normativos", oriundos das Cortes que seriam responsáveis por "dar a última palavra", que são "sempre obrigatórios". Eis, portanto, mais uma simplificação: no Brasil, país que segue a tradição do civil law, parte da doutrina diz que os precedentes são "sempre obrigatórios"; no common law, por outro lado, onde a força do precedente, seja ele vinculante ou não, é tão natural quanto evidentemente mais forte, é um truísmo que não haja qualquer peso absoluto mesmo a precedentes estabelecidos já há muito tempo (BANKOWSKI et. al., 2016, p. 491). ${ }^{2}$ Isso já nos dá uma pista acerca da problemática inaugurada pela doutrina brasileira ao tentar criar um sistema sui generis de mecanismos vinculantes, aos quais, com ares de sofisticação, preferiu denominar de precedentes obrigatórios.

Mas o problema está ainda para além disso, e surge antes. O fato é que, como vimos, a identificação da ratio é um problema de longa data no common law, longe de ter uma solução tão simples. Não por menos, Neil MacCormick (1987, p. 157) reconhece que a identificação da ratio configura a maior dificuldade de se obter um entendimento claro acerca da doutrina do precedente; dificuldade que "confunde" os pensadores jurídicos. Não apenas a ratio é, por vezes, de difícil separação do que é dictum, às vezes sequer é possível localizá-la (DUXBURY, 2008, pp. 69, 71).

Seja como for, com relação às abordagens, de pronto, já se pode mencionar a doutrina de Melvin Eisenberg. Somente ela já destaca três possíveis interpretações acerca da ratio decidendi, o que já denota, no mínimo, uma pluralidade de definições. São elas (i) a abordagem minimalista, (ii) a abordagem focada no resultado, e (iii) a abordagem declaratória. Para a primeira, a regra de um precedente consiste naquela norma enunciada na sentença precedente e que foi necessária à decisão. Desse modo, reduz-se a regra enunciada pela corte ao mínimo indispensável, o que dá a essa abordagem a alcunha de minimalista. Já para a abordagem focada no resultado, a regra de um precedente consiste na proposição segundo a qual, com base nos fatos do precedente (ou alguns deles), deveria ser alcançado o resultado do precedente. $O$ que importa para essa abordagem é o que a Corte fez, e não aquilo que ela disse

2 "Thus, to put it simply, there are [...] grounds in all systems for resisting the ascription of any absolute weight or indefeasibility even to long-settled precedents". 
(EISENBERG, 2010, p. 84). Por fim, a abordagem declaratória considera que a ratio decidendi de um precedente consiste na regra que ele exprime na medida em que seja relevante para as questões levantadas pela controvérsia diante do juiz. Nessa perspectiva, ao enunciar a regra no julgamento do caso - que servirá como precedente - o Tribunal estaria exercendo a função de enriquecimento das normas jurídicas, atividade que, apesar de não ter um valor em si, seria conexa com a função de composição de controvérsias (EISENBERG, 2010, p. 88).

Há, no entanto, como dito, uma série de posições diferentes sobre o tema. Alguns autores dizem que a teoria clássica acerca do conceito de ratio decidendi consiste em considerá-lo a regra ou o princípio que a Corte considera necessário para o resultado encontrado em um caso, ao passo que uma outra visão - tributada a Goodhart - considera a ratio decidendi como sendo os fatos materiais e a decisão judicial que se baseou em tais fatos (SCOFIELD, 2005, pp. 311-328). Nessa perspectiva, importaria mais a decisão e os fatos que lhe são subjacentes que as razões de decidir, ao passo que, na primeira, o que sobreleva é o princípio que serve de base para a decisão. Justamente nesse sentido é a doutrina de Rupert Cross (1977, p. 13), para quem a ratio decidendi é definida pela norma jurídica expressa ou implicitamente tratada pelo juiz como um passo necessário para alcançar sua conclusão judicial. Tem em conta, assim, a linha de raciocínio adotada por ele, como parte necessária para a direção do seu julgamento. A ratio, portanto, deve ser lida de duas formas concomitantes. A primeira, como sendo uma norma jurídica de autoridade obrigatória para o caso em que formulada. E a segunda, como a norma jurídica encontrada no raciocínio atual do julgador, e que expressa a base da sua decisão.

Explica-se: Goodhart (1930) propõe que a ratio decidendi seja determinada a partir da verificação dos fatos, tratados como fundamentais ou materiais pelo juiz. Algumas das visões que divergem dessa proposta, por exemplo, dizem que ela é falha por não levar devidamente em consideração alguns elementos que podem ter influenciado a decisão do juiz, como, por exemplo, a relação do caso em questão com outros casos passados (CROSS, 1977, p. 67). Mesmo assim, e muito embora tenha sido desenvolvida há vários anos, a teoria de Goodhart ainda é considerada por muitos juízes ao decidirem casos em Cortes norte-americanas (DUXBURY, 2008, p. 84). 
Cabe, ainda, dizer que Arthur Goodhart - que, segundo Duxbury (2008, p. 80), verdadeiramente mereceria "um prêmio" por ser pioneiro em "atacar construtivamente" o problema da ratio decidendi - desenvolveu sua teoria de forma a contrapor os realistas jurídicos norte-americanos, ${ }^{3}$ para quem a identificação da ratio e, portanto, toda a lógica do precedente seria mera ilusão (ROSS, 1958, pp. 85-92). Por sinal, a crítica que o realismo jurídico faz aos precedentes judiciais já evidencia a mixagem que no Brasil se faz sobre o tema. Isso porque boa parte dos precedentalistas, ao defender sua doutrina dos precedentes obrigatórios, acaba por reforçar argumentos relacionados ao poder criativo dos juízes - ou seja, a uma defesa de que os juízes criam direito no common law e que, no Brasil, as coisas se passariam do mesmo modo. Desse modo, valem-se em parte de invocações ao realismo jurídico para defender que precedentes obrigatórios seriam necessários para garantir segurança e previsibilidade.

A proposta de Goodhart, apesar de pioneira, passou longe de solucionar o debate. Além de ter sido, como vimos, alvo de algumas críticas - vide, a título de exemplo, as de Julius Stone (1957, pp. 597-620) para quem a ideia de Goodhart, de insistir em dedicar atenção à escolha de fatos materiais feita pelo juiz, não seria satisfatória uma vez que cada um desses fatos pode ser declarado em diferentes níveis de generalização, podendo levar a uma solução distinta para o caso - não foi a única visão a adquirir relevância sobre o tema. Uma versão bastante diferente daquela de Goodhart foi a de Eugene Wambaugh (1894, pp. 17-21), para quem a ratio decidendi deve ser uma regra identificável a partir do elemento da decisão sem o qual o caso em questão deveria ter sido decidido de outra maneira, distinta da que foi. É o chamado "teste de Wambaugh" (DUXBURY, 2008, p. 76). Alguns autores, como, por exemplo, Allen (1939, p. 227) apesar de não adotarem o teste, concedem que a ratio decidendi é um elemento necessário à decisão.

3 O movimento do realismo jurídico norte-americano representou um contraponto à escola de pensamento que dominou o cenário jurídico dos EUA durante um longo tempo. Conhecido como formalismo, a doutrina de Christopher Columbus Langdell dispunha que os princípios gerais do Direito deveriam ser extraídos de precedentes, dos quais sempre seria possível deduzir soluções para os casos futuro. O realismo, por sua vez, propunha uma visão do Direito centrada no papel do juiz na criação do Direito, dando liberdade quase absoluta e retirando qualquer tipo de vinculação ao precedente e, até mesmo, em casos mais extremos, à própria legislação, num sentido de que os juízes deveriam decidir de forma pragmática, prospectiva, atendendo à realidade social (TARELLO, 1962). 
Wambaugh não foi o único. J. L. Montrose, por exemplo, também ofereceu uma contraposição à teoria de Goodhart, ao dispor que sua tese de identificação da ratio, atrelada demasiadamente aos fatos do caso, acarretava na hipótese de a decisão pronunciada pelo juiz fosse ignorada pelas cortes responsáveis por julgar casos subsequentes (GOODHART, 1930, pp. 161-183). A. W. B. Simpson (1958, pp. 155-160), por outro lado, dizia que a tese de Goodhart era incapaz de dizer algo para além da concepção clássica da ratio decidendi, que dispunha, genericamente, que a ratio vinculante é extraída dos "princípios" da decisão.

A conclusão é nítida: ainda que não tenha havido qualquer consenso, e embora a discussão acerca do que constitui a ratio decidendi de um caso seja, em certa medida, indeterminada, evidentemente, em nenhum desses entendimentos é possível equiparar a ratio de um caso a uma tese generalizante, enunciada pelo Tribunal previamente com esse fim. Como vimos, pois, eis aí uma clara - e importantíssima - distinção entre o stare decisis do common law e o "precedente" brasileiro.

Surpreendentemente, o próprio Luiz Guilherme Marinoni (2015, pp. 351-414), em artigo publicado em 2015, não apenas reconhece como expõe muito dessa complexa questão enfrentada pela doutrina do common law no que diz respeito a identificar o que, de fato, constitui a ratio decidendi de uma decisão. $O$ autor refere que "já foi demonstrado que a ratio decidendi, no âmbito do common law, é vista como passo necessário à específica solução dada ao caso". Ao mesmo tempo, porém, curiosamente, em outra publicação anterior, pondera que "[n]o direito brasileiro, contudo, a conformação da ratio decidendi não necessita e não deve sofrer igual restrição", e que "todas as questões, envolvidas e presentes de uma ou outra maneira nos vários processos jurisdicionais, devem contar com os benefícios da teoria dos precedentes" (MARINONI, 2012, pp. 351-414).

Ou seja: com base no(s) artigo(s) de Marinoni, nota-se que muitos daqueles que defendem a tese precedentalista brasileira estão cientes da existência de discussão acerca da identificação da ratio decidendi no common law. ${ }^{4}$ Mesmo sendo

\footnotetext{
4 Como vimos Luiz Guilherme Marinoni chega a abordar e discorrer acerca de algumas das diferentes concepções acerca da identificação da ratio decidendi no âmbito do common law, vide o artigo mencionado e até mesmo sua obra sobre precedentes (MARINONI, 2011, pp. 224-225, 240-245).
} 
a questão reconhecida, porém, no Brasil, ainda assim, insistem que se equipare, de antemão, a ratio à tese jurídica firmada pelas Cortes responsáveis por formar um precedente (MELLO, BARROSO, 2016). Tudo isso enquanto no direito anglo-saxão a identificação se estabelece posteriormente, mediante função interpretativa dos tribunais responsáveis pela aplicação do precedente. Um precedente à brasileira já nasce assim, ao passo que a decisão de uma corte superior anglo-saxã torna-se um precedente. Em um primeiro momento, a decisão cobre somente o caso que está diante da Corte, e seu conteúdo enquanto precedente é desenvolvido posteriormente, quando as cortes subsequentes lidam com casos novos.

Para E. D. Elliott (1983, pp. 125-176), "nenhuma decisão, nem mesmo uma decisão unânime da Suprema Corte, é um precedente no dia em que é proferida". O que torna tal decisão um precedente, pois, é o fato dela ser reconhecida e aceita enquanto um pronunciamento dotado de autoridade, capaz de resolver controvérsias que lhe são futuras. Nesse mesmo sentido, ao comentar o caso Regents of the Univ. of Cal. v. Bakke, ${ }^{5}$ Jan Deutsch (1978) diz que caberia ao futuro dizer se a decisão proferida viria a adquirir "precedential significance" - ou seja, caráter de precedente - ou não. Os autores seguem justamente a ideia que se extrai do que diz o conceito de "precedente" em importantes dicionários do common law: o Black's Law Dictionary estabelece que é um precedente aquilo que for, primeiro, estabelecido por uma corte em um caso particular, e, segundo, "referenciado" posteriormente pelas cortes que decidirem em casos similares (BLACK et. al., 1990, p. 1176); o Bouvier's Law Dictionary, por sua vez, dispõe expressamente que o "binding effect" (efeito vinculante) da ratio decidendi se observa a partir da recorrência de decisões, ${ }^{6}$ afinal, a identificação da ratio é tarefa dos tribunais subsequentes.

É claro que o stare decisis do common law tem relação direta com a autoridade da Corte que prefere a decisão. Entretanto, como visto, a decisão de um tribunal superior passa a ter dimensão de precedente mediante (i) aceitação, primeiro, pelas partes envolvidas no caso que estiver em questão (num sentido de que a

\footnotetext{
${ }^{5}$ Caso em que a Suprema Corte dos EUA decidiu que a raça de um candidato poderia ser um fator a ser levado em consideração da política de admissão na University of California, mas não autorizou que a universidade reservasse cotas específicas pautadas na questão racial (SCOTUS, 1978).

6 "To render precedents valid, they must be founded in reason and justice; must have been made upon argument, and be the solemn decision of the court; and in order to give them binding effect, there must be a current of decisions." (BOUVIER, 1856, p. 364).
} 
decisão do caso alcança as partes nele envolvidas) e, em seguida, (ii) pelas instâncias inferiores, mediante sua incorporação e referência enquanto precedente. Isso fica evidente porque, para além da controvérsia que envolve a questão da identificação da ratio, é nítido o papel dos tribunais subsequentes, responsáveis por aplicar o precedente, nesse processo. Não por menos, acaba-se observando, no common law, até uma certa discricionariedade no que diz respeito a determinar a ratio da decisão pretérita (BRISON, SINOTT-ARMSTRONG, 1993; MARSHALL, 2016, p. 513). Logo, no common law, uma decisão judicial não nasce já com o selo de precedente; é o futuro que dirá a respeito da sua força vinculante; da sua precedential significance.

\section{AS DISTINTAS INTERPRETAÇÕES ACERCA DO PRECEDENTE}

Como visto, a discussão acerca da ratio decidendi, existente no âmbito do common law, foi extremamente simplificada pela tese precedentalista brasileira. Tanto a questão é complexa que, mesmo a doutrina do precedente sendo central em sistemas jurídicos do common law, é unânime que a compreensão teórica acerca dessa prática ainda esteja, nas palavras de Larry Alexander (1989), em um "estágio primitivo", a ponto de enxergar-se até mesmo uma certa "inconsistência" de um discurso interpretativo para outro. ${ }^{7}$ Alguns autores, como Ronald Dworkin (2014, pp. 31-32), chegam a mencionar, inclusive, a existência de uma doutrina estrita e outra atenuada dos precedentes. A primeira obriga os juízes a seguirem decisões anteriores, especialmente dos tribunais superiores, mesmo acreditando que essas decisões foram erradas. Apesar de ser amplamente adotada por juristas do common law - vide a autoridade irrestrita da House of Lords no Reino Unido e da Suprema Corte nos Estados Unidos —, essa visão é contestada por alguns (DWORKIN, 2014, p. 31). Evidentemente, foi essa a doutrina importada pela corrente brasileira que

\footnotetext{
7 É bem verdade que o artigo em que Alexander se refere à profundidade teórica relativa à prática do precedente no common law foi escrito em 1989. Ainda assim, não só as considerações do autor acerca da doutrina do precedente seguem sendo referenciadas, como sua obra posterior segue insistindo no ponto de que há amplas divergências teóricas dizendo respeito à forma como um precedente deve ser interpretado (ALEXANDER, 1996, pp. 493-504). O autor, vale dizer, é um dos que subscrevem, ao lado de autores como Joseph Raz e Frederick Schauer, aquela que será tratada posteriormente como uma das interpretações acerca da doutrina do precedente, vale dizer, a primeira delas, que considera o stare decisis como a imposição de uma regra.
} 
defende a ideia de que o Brasil, agora, trabalha(ria) a partir de um sistema [sic] de precedentes vinculantes.

A segunda doutrina do precedente nos países anglo-saxões é, como dito, a doutrina atenuada, e ela dispõe apenas que o juiz deve atribuir peso a decisões anteriores, e que deve segui-las "a menos que as considere erradas o bastante para suplantar a presunção inicial em seu favor" (DWORKIN, 2014, p. 31). Por óbvio, a discussão é complexa, e não faz parte do objetivo deste trabalho aprofundar-se ou mesmo tecer qualquer tipo de posicionamento em favor de uma ou outra doutrina/corrente doutrinária de juristas do common law; o que se quer demonstrar, contudo, é que essa discussão, orgânica, não é considerada pela importação mecânica e desprovida de questionamento por parte do precedentalismo nacional.

O que se vê é que a discussão doutrinária sobre o precedente, sua força, alcance, papel e até mesmo interpretação, no common law, portanto, é ampla. À luz do debate sobre a ratio decidendi, há, também, no mesmo sentido, um outro debate, que, em linhas gerais, vai decorrer exatamente das diferentes interpretações acerca do que constitui a ratio em uma decisão; enquanto que o debate sobre a ratio já elencava o que constituiria exatamente o núcleo fundamental do precedente, este segundo, por sua vez, acaba por dar voz a três interpretações distintas acerca de como o precedente deve ser entendido, quais sejam: (i) o precedente como regra imposta (rule-stating model); (ii) o precedente como a aplicação de princípios subjacentes à decisão (principle-exemplifying model); e (iii) o precedente como uma decisão a partir do balanço de razões existentes na decisão do caso individual, ou de analogia particular (model of particular analogy). De pronto, assim, já se pode perceber a complexidade do tema e, portanto, a simplificação excessiva operada pela doutrina brasileira. Para cada um desses modelos, haverá divergências quanto à forma por meio da qual os precedentes devem ser tomados - sempre a partir de seus casos - como vinculantes. Há quem diga que isso deve ser dado de acordo com seus fatos particulares, como em um modelo de analogia; há quem sustente que a ratio também, em alguma medida, explicita uma regra determinada; há quem sustente que a vinculação deve dar-se através dos princípios que estão pressupostos e podem ser extraídos a partir da fundamentação da decisão. 
De acordo com uma corrente, encabeçada por autores como Frederick Schauer, o precedente judicial é entendido enquanto uma regra. O que se quer explicitar quando se defende que a decisão judicial que constitui o precedente dispõe uma regra? Suponhamos que determinada Corte se veja diante de um caso em que o autor postula pelo resultado (a) trazendo as razões (a1), (a2) e (a3). O réu, por sua vez, postula pelo resultado (b), alegando (b1), (b2) e (b3). Ao decidir em favor do resultado (a) e dispor que as razões (a1) e (a3) foram as razões determinantes para a solução do caso, a Corte estará dizendo que sempre que (a1) e (a3) ocorrerem no plano prático, o resultado da disputa deve ser (a). Ou seja: em outras palavras, ao decidir uma disputa particular, a Corte estará criando uma regra através da qual se resolve aquele tipo de disputa (LAMOND, 2011). Esse é, portanto, o modelo chamado de rule-stating: a ratio constitui uma regra que deve ser aplicada exceto nas hipóteses óbvias de distinguishing ou overruling. Havendo uma ratio relevante, e não havendo razão em contrário, o que se extrai como precedente constitui uma regra (BANKOWSKI et. al., 2016, p. 497).

A grande crítica à interpretação do precedente como regra disposta diz respeito exatamente ao papel dos tribunais subsequentes na identificação da ratio decidendi. No common law, como vimos, os pronunciamentos das Cortes no julgamento de casos, por mais diretos que sejam, raramente identificam de forma direta suas próprias rationes. A vinculação, portanto, se dá a partir do precedente. Ademais, ainda que uma Corte decida expor a ratio, não é essa formulação específica que vincula os tribunais posteriores (MOORE, 1987, pp. 183-198). Como se pode ver, as críticas a essa interpretação específica, que em muito se aproxima da proposta precedentalista brasileira, é criticada no common law a partir de um fundamento por meio do qual já se pode afastar, de pronto, a ideia de um sistema brasileiro de precedentes: o estabelecimento de teses, aprioristicamente, não têm o condão de vincular de antemão o tribunal que segue - do contrário, teríamos que admitir que juízes e Tribunais exercem função legislativa, algo que por óbvio exigiria, no mínimo, uma profunda reforma constitucional.

Diante dos problemas - como vimos, apontados por doutrinadores inseridos no próprio contexto anglo-saxão - existentes na interpretação do precedente como uma regra imposta, surge uma outra corrente propositiva de uma maneira distinta de 
se compreender o fenômeno: a interpretação do precedente como a aplicação dos princípios subjacentes à decisão do tribunal que a tiver proferido. ${ }^{8}$ De certa maneira, poder-se-ia até dizer que essa interpretação tem certa ligação com a já mencionada doutrina atenuada do precedente, referida por Ronald Dworkin em O Império do Direito, já que, na mesma linha, a ratio da decisão seria não uma regra disposta, mas apenas uma forma mais rápida e conveniente através da qual se pode referir-se aos princípios que justificaram a decisão no caso concreto (PERRY, 1987, pp. 223-230).

Essa interpretação oferece uma explicação para a prática do distinguishing i.e. quando a Corte responsável pela aplicação do precedente diferencia os fatos materiais do caso em análise daqueles que foram objeto da decisão anterior - de forma mais adequada que a interpretação do precedente como regra, já que aquela é incapaz de dar conta dos motivos pelos quais pode-se utilizar o distinguishing mesmo quando os fatos apontados como distintos não estejam expressamente previstos na própria ratio. Por outro lado, se a vinculação do precedente puder ser explicada através dos princípios subjacentes à decisão, o distinguishing nesse tipo de situação é facilmente explicável na medida em que um caso subsequente é passível da prática quando a justificativa para o resultado atingido na decisão precedente não é capaz de ser razoavelmente aplicada aos fatos distintos que estiverem em questão, ainda que presente na ratio da decisão (LAMOND, 2011).

É nesse sentido, portanto, que a aplicação do precedente (que, sob essa perspectiva, é nada mais que uma decisão entendida como regra no caso específico que tiver solucionado) e sua interpretação se dá através da melhor justificação dos princípios subjacentes à decisão em questão. Segundo Dworkin (2001, p. 238), no common law - onde "nenhuma lei ocupa posição central na questão jurídica" - "o argumento gira", justamente, "em torno de quais regras ou princípios [...] 'subjazem' a decisões de outros juízes no passado". O juiz responsável pela aplicação do precedente deve verificar por que os princípios por trás dos casos precedentes exigem também uma decisão em certa direção nos casos subsequentes (DWORKIN, 2001, p. 172).

8 Para uma explanação acerca dessa doutrina, há diversas fontes excelentes (PERRY, 1987; MOORE, 1987; DWORKIN, 2014). 
Esse é, segundo Bankowski et. al., o modelo "exemplificativo de princípio" (2016, p. 497). De acordo com essa interpretação, o precedente, em relação ao contexto factual do caso que lhe serviu de origem - repare-se que, lá, o caso está sempre presente —, não apenas exibe como serve de suporte a princípios jurídicos que, em razão de seu papel no ordenamento, podem (e devem) ter relevância na decisão de casos futuros. Os tribunais subsequentes olham para os precedentes (no sentido lato, de decisões pretéritas) e, quando da identificação do que constitui a ratio, verificam se eles representam princípios suficiente e adequadamente justificatórios quanto à decisão a ser tomada no caso que estiver em questão.

Naturalmente, esse é um modelo bastante mais aberto, de modo que é criticado e, precisamente por isso, também não é unânime. Assim, a terceira das três interpretações dominantes acerca doutrina do precedente no âmbito do common law aqui abordadas dá-se na constituição do que viria a ser a ratio decidendi a partir do balanço (do inglês balance, que, talvez com certa imprecisão, poderia também ser traduzido como equilíbrio) das razões que justifica(ra)m a decisão precedente no caso concreto em questão e que deve ser tratada (e, consequentemente, seguida) pelas cortes subsequentes como correta. Grant Lamond, por exemplo, é um dos autores que rejeita a ideia de que o precedente crie uma regra, e, consequentemente, entende que o common law não pode ser definido como um sistema cuja própria ideia de formação decisória seja pautada através da criação de regras. Em vez disso, Lamond considera que o common law é um sistema de decisões "case-by-case", ou, em tradução livre, caso a caso (LAMOND, 2005).

A diferença dessa interpretação para a que entende o precedente como a disposição de uma regra reside no fato de que se a ratio (e, portanto, o efeito vinculante da decisão) for entendida não como uma regra per se, mas entendida como um balanço das razões através das quais a Corte responsável pelo precedente chegou à decisão, os tribunais subsequentes estão vinculados - como bem observou Lamond (2011) - não somente a rationes, mas a casos, e estão obrigados a seguilos ou, não sendo o caso, praticar o distinguishing. Isso quer dizer que a corte posterior, ao deparar-se com um caso cujos fatos encontram-se no escopo da ratio em questão, devem considerar o precedente, mas de forma a considerar se as diferenças de um caso a outro justificam que estes sejam decididos de forma distinta. 
Esse é o modelo de "analogia particular" (BANKOWSKI et. al., 2016, p. 497), no qual cada caso é tratado como um exemplo de decisão acertada, considerados todos os fatos, servindo então de modelo aos casos subsequentes. O problema, aqui, residiria no seguinte ponto: em qual grau de detalhamento deve ser feita a comparação entre os casos - pretérito e presente? São críticas como essa (levantadas, é claro, a qualquer que seja a interpretação tomada) que tornam muito clara a razão por que não há unanimidade no modo pelo qual se enxerga a vinculação do precedente anglosaxão.

Ainda com Bankowski et. al. (2016, pp. 498-499), é possível dizer (i) que é possível falar em modelos nos quais o precedente não é reconhecido como formalmente vinculante; (ii) que, quando for esse o caso, as interpretações do instituto como princípios subjacentes ou como analogia particular terão precedência sobre o rule-stating model; (iii) que precedentes podem ser utilizados como analogias ou ilustrações de princípios jurídicos sem que seja necessário conferir-lhe caráter de fonte formal de Direito; (iv) que, nos EUA, a interpretação principiológica e o modelo de analogia particular têm precedência sobre o modelo de regras, ao passo que, no Reino Unido, embora o common law tenha se desenvolvido mais a partir dessas mesmas duas abordagens, a teoria britânica do precedente vem sendo fortalecida a partir de uma interpretação do precedente como regra disposta pela Corte. Eis, pois, mais uma reflexão ignorada pela tese precedentalista brasileira.

\section{A RECEPÇÃO NO BRASIL}

A partir de todas essas interpretações, notamos, agora mais claramente, uma diferença absolutamente significativa entre o nosso sistema e aquele do common law: a própria referência aos casos pretéritos. Apenas a título de exemplo, neste primeiro momento, tomemos apenas três casos marcantes nos sistemas anglo-saxões: o já mencionado Regents of the University of California v. Bakke (SCOTUS, 1978), Riggs v. Palmer (NEW YORK STATE UNIFIED COURT SYSTEM, 1889) e Marbury v. Madison (SCOTUS, 1803). Agora, observemos três recentes casos marcantes diante de nosso Supremo Tribunal Federal (2016 e 2011): HC 126.292, HC 124.306 e ADI 
4.277. Não está aí, pois, uma notável incompatibilidade entre os dois sistemas? Se um deles (obviamente, o anglo-saxão) permite uma interpretação que relacione o efeito vinculante do precedente a, especificamente, casos, facilmente identificáveis, é mais que evidente que o sistema jurídico brasileiro passa longe dessa possibilidade.

Para além desse problema inicial, quando nos questionamos sobre qual dessas diferentes interpretações a doutrina brasileira adota, é importante observar que Marinoni, Arenhart e Mitidiero mencionam algo próximo à interpretação que analisamos por último, com o precedente visto como as razões da decisão servindo de modelo - frise-se, como se única fosse - ao mesmo tempo em que o resto de seu discurso não parece adequar-se a ela. Os autores dizem que "a ratio decidendi constitui uma generalização das razões adotadas como passos necessários e suficientes para decidir". Nenhum problema até aí. Curiosamente, contudo, repetem o que havia dito Marinoni anteriormente, já aqui referenciado, ao observar que "nada justifica semelhante restrição [qual seja, a de que a ratio sirva para solução de casos e não de questões] diante do direito brasileiro" (MARINONI et. al., 2015, p. 613). discurso precedentalista brasileiro, pois, menciona uma das interpretações acerca da doutrina do precedente - o modelo de analogia particular —, alinha seu discurso com outra - o precedente visto como regra disposta — , e ignora uma terceira - a interpretação do precedente a partir dos princípios que subjazem às razões de decidir.

A título de observação, ainda, antes de se finalizar a exposição acerca das nuances existentes na doutrina do precedente no common law, cabe mencionar, brevemente, o instituto do per incuriam - do latim, "por falta de cuidado". O per incuriam, como a própria tradução da locução já sugere, é um instituto típico do sistema jurídico anglo-saxão que caracteriza decisões formadas a partir de uma apreciação inadequada do Direito ou da análise dos fatos que estiverem em questão diante da Corte responsável pela matéria (UNIVERSITY OF OXFORD, 2017). Isso significa que uma decisão proferida de forma a contradizer (ou, especialmente no caso do common law, desconsiderar) a legislação ou um precedente, já constituído como obrigatório a partir da identificação das cortes subsequentes, será considerada per incuriam e, portanto - obviamente, com o devido ônus argumentativo —, os tribunais subsequentes podem desobrigar-se de seguir o precedente. 


\section{CONCLUSÃO}

Assim, feitas essas reflexões, chega-se à conclusão de que, diferentemente do que ocorre no Brasil, há um amplo debate, histórico, antigo, sobre a questão dos precedentes no Direito anglo-saxão. O primeiro deles diz respeito à identificação do que constitui a ratio decidendi de uma decisão que, posteriormente, formará o precedente. Para Goodhart, como visto, a ratio decidendi deve ser determinada a partir da verificação dos fatos, tratados como fundamentais ou materiais pelo juiz Wambaugh, por sua vez, por exemplo, defendia que a ratio deve(ria) ser uma regra identificável a partir do elemento da decisão sem o qual o caso em questão deveria ter sido decidido de outra maneira, distinta da que foi, no que seria, posteriormente, chamado de "teste de Wambaugh".

A partir desse debate sobre a própria ratio decidendi, portanto, na common law, a própria ideia de precedente será interpretada de forma diferente por diferentes autores. Alguns trabalham com uma ideia do precedente como regra. Enquanto isso, outros autores anglo-saxões entendem que a parte vinculante de um precedente se dá a partir dos princípios subjacentes à decisão que o originou, e, portanto, que a ratio não expressa, em si, uma regra disposta. Além disso, ainda, outros autores consideram que o efeito vinculante do precedente se dá a partir de um balanço das razões que determinaram que a decisão, e não a partir da ratio pura e simplesmente.

O que se conclui, portanto, é que a tese precedentalista, ao defender que o Brasil teria adotado um "sistema" $[\mathrm{sic}]$ de precedentes vinculantes, não considera todas as nuances e idiossincrasias de um debate histórico que se desenvolve(u) no âmbito do common law até os dias atuais. Consequentemente, as teses abstratas e generalizantes do Direito brasileiro aproximam-se muito pouco do precedente, legítimo, do common law, ao trabalharem com a ideia de que a(s) Corte(s) "Suprema(s)" seria(m) responsável(is) por interpretar e, aos tribunais subsequentes - que, no common law, por sua vez, são responsáveis justamente por constituir o que vem a, posteriormente, ser o efeito vinculante na decisão pretérita - , restaria apenas uma tarefa mecânica de "aplicação". A tese precedentalista brasileira, portanto, além de incorrer em alguns erros teóricos, não considera a complexidade de 
um debate histórico sobre a doutrina do precedente no common law e, mais que isso, insiste na ideia de que é possível cindir aplicação e interpretação.

É um consenso no common law - algo que, curiosamente, parece ser, muitas vezes, ignorado por aqui - que os tribunais subsequentes têm flexibilidade para determinar a ratio específica de cada decisão precedente (LAMOND, 2011). Mais do que isso, atente-se para o seguinte: no common law, até mesmo autores que adotam a intepretação do próprio conceito de precedente como a disposição de uma regra afirmam categoricamente que o sistema de precedentes vinculantes não se encaixa adequadamente em um sistema jurídico plenamente constitucional/estatutário. Ao tratar do precedente nos Estados Unidos, Larry Alexander (1989) diz que é preciso reconhecer que o precedente vinculante tem um "fit", ou "ajuste", "difícil" em países sob o civil law, algo que não é problemático em razão de o sistema americano ser aquilo que o autor chama de sistema constitucional "impuro".

Os exemplos não param por aí. O próprio H. L. A. Hart (2012, p. 165), talvez o mais importante autor no positivismo jurídico - autor este que trabalhou com maestria a complexidade no estudo da teoria do Direito, abordando a semântica e a pragmática - diz que "[a] inclusão de um caso particular dentro de uma norma e a inferência de uma conclusão silogística já não caracterizam a essência do raciocínio envolvido em decidir qual é o procedimento correto". O autor segue, dizendo que por mais que "a linguagem da norma" parece "apenas assinalar um exemplo vinculante", ela "limita os traços que exigem atenção" de "maneira simultaneamente mais permanente e mais rigorosa que o precedente". É interessante observar que, no Brasil, ao contrário, Mitidiero (2013, p. 58) chega a dizer que "a interpretação é um processo que visa à redução da equivocidade do enunciado e definição da norma que se ultima mediante uma escolha — ainda que lógica e argumentativamente guiada do intérprete, o seu resultado não pode ser qualificado como exato, correto ou único possível'. Ora, Hart (2012, p. 188) diz não só que a regra legislativa, per se, limita os traços de forma muito mais rigorosa que o precedente, mas também que os juízes "fazem parte de um sistema cujas normas são, em seu cerne, suficientemente precisas para oferecer padrões de decisão judicial correta”. Ainda no mesmo sentido, o precedentalismo brasileiro parece afastar-se mais ainda do stare decisis legítimo do common law na medida em que simplifica em demasia a questão de suas concepções 
definitórias mais básicas, especialmente quando lembramos - como já vimos a partir das diversas interpretações acerca do stare decisis - que "não existe um método único para se determinar a norma derivada de certo precedente autorizado" (HART, 2012, p. 174).

Mais ainda, ao atribuir ao precedente, frise-se, no civil law, um peso similar ao da lei em um ordenamento jurídico, a tese precedentalista brasileira parece caminhar, justamente e uma vez mais, na direção contrária à do common law. Nesse último, a legislação sempre se sobrepõe ao precedente. Isso pode ser depreendido novamente das lições de Hart (2012, p. 183), que dispõe que "a decisão pode, naturalmente, ser privada de efeito jurídico por meio da legislação". O mesmo acontece nos Estados Unidos, onde, assim como a Constituição tem precedência sobre qualquer outra fonte de lei, também o direito estatutário deve sobrepor-se ao precedente em eventual conflito: é o que sustenta Summers (2016, p. 365), quem diz ainda que, no país diferentemente do que ocorreria no Brasil à maneira como ilustra a doutrina precedentalista - , não é sempre que a disposição que vem a ser vinculante em um precedente (no caso norte-americano, a holding) é disposta de antemão de maneira clara pela Corte (SUMMERS, 2016, pp. 383-385; GREENAWALT, 1989, pp. 439-442). O sistema brasileiro de "teses" seria, pois, uma anomalia em qualquer país do common law. No Brasil, por sua vez, tem-se construído um sistema recursal que impede as partes de rediscutir as decisões vinculantes das Supremas Cortes, assim como juízes e Tribunais inferiores de divergirem do "precedente vinculante". Consequentemente, somente a própria "Corte de Precedentes" poderia revogar um precedente, estando os demais juízes e tribunais a ele submetidos, ainda que se trate de um "precedente" contrário à lei ou à Constituição. Ora, o raciocínio é simples: o juiz não resolve a relação jurídica de direito material controvertida aplicando propriamente o precedente, mas a lei à qual o precedente se reporta. É a lei que fixa a norma de conduta às partes, e não o precedente. Consequentemente, s se a lei for revogada ou tiver o seu sentido alterado no curso do tempo, o precedente terá perdido — no todo ou em parte - o seu objeto. Se não é isso que quer dizer, então o artigo 927 do CPC de 2015 será inconstitucional, pois estará criando uma nova modalidade de norma 
geral e abstrata à margem da CF/1988. ${ }^{9}$ Especialmente porque sequer no common law a Corte age como se legislatura fosse, determinando regras generalizáveis e prospectivas; fosse assim, correr-se-ia o risco de uma passagem do rule of law para uma espécie de law of precedents (FARBER, 2005, p. 1203).

Isso é o que nos leva à reflexão final. O que é, simplesmente, essencial, é insistir uma vez mais em um ponto subjacente às reflexões deste ensaio, que é ignorado pela doutrina precedentalista brasileira: um precedente legítimo não nasce precedente. A aplicação da decisão pretérita por parte do tribunal subsequente é, sempre, uma atividade reconstrutiva (BUSTAMANTE, 2016, pp. 288-289). Dito de outro modo, significa que a recepção da decisão anterior, sua reconstrução fáticonormativa, e sua posterior aplicação enquanto precedente é uma tarefa (i) incindível e, mais, (ii) que é papel do tribunal subsequente. Em todo esse processo, o tribunal responsável pela aplicação do precedente não está tão somente reaplicando premissas normativas; ao contrário, a aplicação da decisão pretérita pressupõe, sempre a necessidade de se decidir "acerca da força argumentativa que deve ser atribuía à ratio decidendi a ser utilizada como elemento de justificação de um caso ainda não solucionado" (BUSTAMANTE, 2016, p. 289). É o tribunal subsequente que, interpretando e aplicando, dispõe a delimitação da ratio decidendi do (que virá a ser o) precedente. A Corte responsável pela decisão (em tese) vinculante, em um sistema de precedentes legítimo, não tem essa visão prospectiva; no common law, expectativas são formadas não porque um juiz de Corte Suprema ou Superior faz uma tentativa explícita de criar um precedente, mas porque se espera para ver como os juízes subsequentes respondem e responderão à decisão do juiz responsável por aquela que formou o precedente. Não é sem razão que, por exemplo, é possível verificar juízes e tribunais do presente concluindo que, aquilo que outrora foi considerado como ratio decidendi da decisão não o era de fato (DUXBURY, 2008, p. 73). O mesmo Duxbury (2008, p. 74) segue dizendo que o fato de a identificação da ratio ser tão contestável ilustra o quanto os precedentes podem ser "maleáveis"; é na identificação da ratio por parte do juiz posterior, que pode selecionar entre duas ou

${ }^{9}$ Devemos este ponto às reflexões de Eduardo José da Fonseca Costa. 
mais possíveis rationes de caso a caso, que esses juízes próprios estão a determinar o verdadeiro significado da autoridade do precedente. ${ }^{10}$

É possível uma palavra final. Fiquemos com a seguinte lição: no Brasil, a doutrina precedentalista sustenta teses abstratas, prospectivas e generalizáveis, com força de lei, como se precedentes fossem; no common law, não apenas há diversas abordagens sobre o significado do precedente, é o tribunal subsequente que será responsável por determinar a norma jurídica em questão. Um precedente não nasce precedente. Torna-se (STRECK, 2018, p. 76).

\section{REFERÊNCIAS}

ALEXANDER, Larry. Constrained by Precedent. In: Southern California Law Review, v. 63, n. 1. Berkeley: University of California Press, nov. 1989, pp. 01-65. Disponível em: <http://www.umiacs.umd.edu/ horty/courses/readings/alexander1989-constrained-precedent.pdf>.

. Precedent. In: PATTERSON, Dennis (ed.). A Companion to the Philosophy of Law and Legal Theory. Oxford: Blackwell, 1996, pp. 493-504

ALLEN, Carleton Kemp. Law in the Making, 3. ed. Oxford: Clarendon Press, 1939.

BARROSO, Luís Roberto. O Controle de Constitucionalidade no Direito Brasileiro. 7. ed. Rio de Janeiro: Saraiva, 2015.

BANKOWSKI, Zenon; MACCORMICK, Neil; MORAWSKI, Lech; RUIZ MIGUEL, Alfonso. Rationales for Precedent. In: MACCORMICK, Neil; SUMMERS, Robert S. GOODHART, Arthur L. Interpreting Precedents. Nova York: Routledge, 2016.

BLACK, Henry Campbell; NOLAN, Joseph R.; NOLAN-HALEY, Jacqueline M. Black's Law Dictionary. 6 ed. St. Paul: West Publishing Co., 1990.

BOUVIER, John. A Law Dictionary, adapted to the Constitution and Laws of the United States of America and of the Several States of the American Union, with references to the Civil and other systems of Foreign Law. 6. ed. Filadélfia: Childs \& Peterson, 1856.

10 "But the fact that a ratio can be contested illustrates how judicial precedents may prove malleable, for in those instances where later courts select a ratio from two or more possible rationes within a case, they are determining for what authority the precedent should stand" (DUXBURY, 2008, p. 74). 
BRASIL. Supremo Tribunal Federal. Ação Direta de Inconstitucionalidade 4.277 Distrito Federal, mai. $2011 . \quad$ Disponível em: $<$ <ttp://redir.stf.jus.br/paginadorpub/paginador.jsp?docTP=AC\&doclD=628635>.

Habeas Corpus 124.306 Rio de Janeiro, nov. 2016. Disponível em: <http://www.stf.jus.br/arquivo/cms/noticiaNoticiaStf/anexo/HC124306LRB.pdf>.

Habeas Corpus 126.292 São Paulo, fev. 2016. Disponível em: $<$ http://redir.stf.jus.br/paginadorpub/paginador.jsp?docTP=TP\&docID=10964246>.

BRISON, Susan J. SINOTT-ARMSTRONG, Walter. A Philosophical Introduction to Constitutional Law. In: BRISON, Susan J. SINOTT-ARMSTRONG, Walter (ed.). Contemporary Perspectives on Constitutional Interpretation. Boulder: Westview Press, 1993.

BUSTAMANTE, Thomas da Rosa. Teoría del Precedente Judicial: La Justificación y la Aplicación de Reglas Jurisprudenciales. Lima: Legales, 2016.

CAENEGEM, R. C. van. Juízes, legisladores e professores: capítulos de história jurídica europeia: palestras Goodhart 1948-1985. Tradução Luiz Carlos Borges; revisão técnica Carla Henriete Bevilacqua. Rio de Janeiro: Elsevier, 2010.

COLLIER, Charles W. Precedent and Legal Authority: A Critical History. In: Wisconsin Law Review. Madison, 1988, n. 771. Disponível em $<$ http://scholarship.law.ufl.edu/facultypub/675>.

CROSS, Rupert. Precedent in English Law. Oxford: Clarendon Press, 1977, p. 13.

CRUZ E TUCCI, José Rogério. Precedente Judicial como Fonte do Direito. São Paulo: RT, 2004.

DEUTSCH, Jan G. Law as Metaphor: A Structural Analysis of Legal Process. In: The Georgetown Law Journal, v. 66, n. 6. Washington: Georgetown University Law Center, 1978.

DIDIER JUNIOR, Fredie. O Recurso Extraordinário e a Transformação do Controle Difuso de Constitucionalidade no Direito Brasileiro. Revista Páginas de Direito, Porto Alegre, ano 13, № 1085, 09 de outubro de 2013. Disponível em: <http://www.tex.pro.br/listagem-de-artigos/47-artigos-set-2010/6309-a-valoracao-daprova-e-a-verossimilhanca-nas-medidas-de-urgencia>.

DUXBURY, Neil. The Nature and Authority of Precedent. Cambridge: Cambridge University Press, 2008.

DWORKIN, Ronald. Levando os direitos a sério. Tradução de Nelson Boeira. 1 ed. São Paulo: Martins Fontes, 2002. 
Martins Fontes, 2014.

O Império do Direito. Tradução de Jefferson Luiz Camargo. São Paulo: . Uma questão de princípio. São Paulo: Martins Fontes, 2001.

ELLIOTT, E. Donald. INS v. Chadha: The Administrative Constitution, the Constitution, and the Legislative Veto. In: The Supreme Court Review, v. 1983. Chicago: University of Chicago Press, 1983, pp. 125-176.

EISENBERG, Melvin Aron. La Natura del Common Law. Foggia: Università degli studi di Foggia, 2010.

FARBER, Daniel A. The rule of law and the law of precedents. Minnesota Law Review, v. 90, jan. 2005, pp. 1173, 1203.

GOODHART, Arthur L. Determining the ratio decidendi of a case. In: The Yale Law Journal, vol. 40, n. 2, dez. 1930, pp. 161-183.

GREENAWALT, Kent. Reflections on Holding and Dictum. Journal of Legal Education, v. 39, n. 03, set, 1989, pp. 431-442.

HART, H. L. A. O Conceito de Direito. Tradução de Antônio de Oliveira Sette Câmara. 1 ed. São Paulo: WMF Martins Fontes, 2012.

LAMOND, Grant. Precedent and analogy in legal reasoning. In: ZALTA, Edward N. (ed.). The Stanford Encyclopedia of Philosophy. Spring 2016 ed. Stanford: Metaphysics Research Lab, Stanford University, 2011. Disponível em: <https://plato.stanford.edu/archives/spr2016/entries/legal-reas-prec/>.

LOPES FILHO, Juraci Mourão. Os Precedentes Judiciais no Constitucionalismo Brasileiro Contemporâneo. Salvador: Juspodivm, 2016.

MACCORMICK, Neil. Why cases have rationes and what these are. In: Precedent in Law. Oxford: Clarendon Press, 1987.

MARINONI, Luiz Guilherme. Curso de Processo Civil: Teoria Geral do Processo. São Paulo: Revista dos Tribunais, 2006.

. Precedentes Obrigatórios. São Paulo: RT, 2010, p. 101.

. Uma nova realidade diante do Projeto de CPC: a ratio decidendi ou os fundamentos determinantes da decisão. In: Revista dos Tribunais, v. 101, n. 918, pp. 351-414, abr. 2012.

MARINONI, Luiz Guilherme; ARENHART, Sérgio Cruz; MITIDIERO, Daniel. Novo Curso de Processo Civil: Tutela dos Direitos Mediante Procedimento Comum, vol. 2. São Paulo: Revista dos Tribunais, 2015. 
MARSHALL, Geoffrey. What is Binding in a Precedent. In: MACCORMICK, Neil; SUMMERS, Robert S. GOODHART, Arthur L. Interpreting Precedents. Nova York: Routledge, 2016.

MELLO, Patrícia Perrone Campos; BARROSO, Luís Roberto. Trabalhando com uma nova lógica: a ascensão dos precedentes no Direito brasileiro. In: Revista da AGU, v. 15, n. 3. Brasília: Fórum, jul./set. 2016, pp. 9-52.

MITIDIERO, Daniel. Cortes Superiores e Cortes Supremas: do controle à interpretação, da jurisprudência ao precedente. São Paulo: Revista dos Tribunais, 2013.

. Daniel. Precedentes: da persuasão à vinculação. São Paulo: RT, 2016.

MOORE, Michael. Precedent, induction, and ethical generalisation. In: GOLDSTEIN, Laurence (ed.). Precedent in law. Oxford: Oxford Clarendon Press, 1987, pp. 183198.

NEW YORK STATE UNIFIED COURT SYSTEM. 115 N.Y. 506 (1889). Disponível em: <http://www.courts.state.ny.us/reporter/archives/riggs_palmer.htm>.

PERRY, Stephen R. Judicial obligation, precedent and the common law. Oxford Journal of Legal Studies. Oxford, v. 7, n. 2, jul. 1987, pp. 215-257. Disponível em: $<$ https://doi.org/10.1093/ojls/7.2.215>.

ROSS, Alf. On Law and Justice. Londres: Stevens \& Sons, 1958.

SCOFIELD, Robert G. Goodhart's Concession: Defending Ratio Decidendi From Logical Positivism and Legal Realism in the First Half of the twentieth Century. In: The King's College Law Journal, v. 16, 2005, pp. 311-328.

SCOTUS. 5 U.S. $\quad(1 \quad$ Cranch) $137 \quad$ (1803). Disponível em <https://supreme.justia.com/cases/federal/us/5/137/case.html/>.

$438 \quad$ U.S. $265 \quad$ (1978). Disponível em

<https://supreme.justia.com/cases/federal/us/438/265/>.

SIMPSON, Alfred W. Brian. Determining the ratio decidendi of a case. In: Modern Law Review, vol. 21, n. 2, mar. 1958, pp. 155-160.

STONE, Julius. The ratio of the ratio decidendi. The Modern Law Review, v. 22, n. 06. Oxford, pp. 597-620, nov. 1959.

STRECK, Lenio Luiz. O que é isto - o sistema (sic) de precedentes no CPC? Revista Consultor Jurídico. São Paulo: 18 ago. 2016. Disponível em: <http://www.conjur.com.br/2016-ago-18/senso-incomum-isto-sistema-sicprecedentes-cpc>. 
Precedentes Judiciais e Hermenêutica: o sentido da vinculação no CPC/2015. Salvador: Juspodivm, 2018.

STRECK, Lenio Luiz. ABBOUD, Georges. O solilóquio epistêmico do ministro Roberto Barroso sobre precedentes. In: Revista Consultor Jurídico. São Paulo: 03 nov. 2016. Disponível em: <http://www.conjur.com.br/2016-nov-03/senso-incomum-soliloquioepistemico-ministro-barroso-precedentes>.

SUMMERS, Robert S. Precedent in the United States (New York State). In: MACCORMICK, Neil; SUMMERS, Robert S. GOODHART, Arthur L. Interpreting Precedents. Nova York: Routledge, 2016.

TARELLO, Giovanni. II realismo giuridico americano. Milano: Giuffrè, 1962.

TARUFFO, Michele. Aspetti del precedente giudiziale. In: Criminalia: Annuario di Scienze Penalistiche. Pisa: Edizioni ETS, 2014, pp. 37-57.

UNIVERSITY OF OXFORD. Per incuriam. In: UNIVERSITY OF OXFORD. The Oxford English Dictionary. Oxford: Oxford University Press, 2017. Disponível em: $<$ https://en.oxforddictionaries.com/definition/per_incuriam>.

WAMBAUGH, Eugene. The study of cases: a course of instruction in reading and stating reported cases, composing head-notes and briefs, criticising and comparing authorities, and compiling digests. 2. ed. Boston: Little, Brown \& Co., 1894. 